Patients with moderate pain (52\%) received dypirone $19 \mathrm{mg} / \mathrm{kg} \mathrm{q}$ 6 hours (86\%) and tramadol $1.1 \mathrm{mg} / \mathrm{kg} \mathrm{q} 4-8 \mathrm{~h}(95 \%)$ and morphine $0.1 \mathrm{mg} / \mathrm{kg}$ every $3-6$ hours (33\%).

Patients with severe pain $(37.5 \%)$ received dypirone $19 \mathrm{mg} / \mathrm{kg} \mathrm{q}$ 6 hours $(93 \%)$ and tramadol $1.2 \mathrm{mg} / \mathrm{kg} \mathrm{q} 4-8 \mathrm{~h}(93 \%)$ and morphine $0.1 \mathrm{mg} / \mathrm{kg}$ every 3-6 hours (60\%).

Patients who received tramadol i.v. in intervals over 6 hours (12.5\%), and received morphine i.v.in intervals over 4 hours $(10 \%)$ had moderate and intense pain.

Conclusions Tramadol and morphine i.v. should not be administered in intervals longer than 6 hours for tramadol and 4 hours for morphine due to its half life. (Tramadol T1/2:5.5.h and morphine T1/2: 2 hours).

Since dypirone inhibits cicloxigenase and reduces tromboxane levels in platelets, antiagregant effect should be evaluated in sickle cell disease patients.

\section{HEPATITIS A IN PEDIATRIC WARD (EXPERIENCE IN THE PEDIATRIC SERVICE OF CHU OF BATNA)}

doi:10.1136/archdischild-2012-302724.1532

ND Righi, S Brahmi, H Zerguine, H Soltani, S Tebbal. CHU Benflis Touhami, Universite de Batna, Park Aforage, Algeria

Introduction Hepatitis $A$ is a real public health problem worldwide: 273 confirmed cases in Algeria in 2010. She is responsible for $10-30 \%$ of hepatitis in adults and $70-90 \%$ in children.

Objectives To determine the frequency and severity of hepatitis A. Materials and Methods A retrospective study done on the records of patients hospitalized for complicated form of hepatitis A over a period of 02 years (2009-2010). 28 patients hospitalized for complicated forms: signs of liver failure.

Results Incidence: $1.15 \%$.

Age group affected is between 5-10 years with a female predominance.

In Algeria the transmission is the predominant waterborne, mostly occurring in winter. Fever, vomiting and asthenia constitute $68.74 \%$ of the reasons for consultation. The average AST, ALT was elevated 100 times normal.

Conclusion Hepatitis A is very common in Algeria in connection with a water-borne and the majority of cases are asymptomatic and almost at the age of 18 years $95 \%$ of patients develop antibodies.

\section{EPIDEMIOLOGICAL PROFILE OF URINARY TRACT INFECTION IN PEDIATRIC WARD (EXPERIENCE OF A PEDIATRIC SERVICE OF THE UNIVERSITY HOSPITAL OF BATNA)}

doi:10.1136/archdischild-2012-302724.1533

HD Zerguine, S Brahmi, S Taleb, S Tebbal. Sciences Médicales de Batna, CHU de Batna, Logements, Algeria

Introduction Urinary tract infection (UTI) is one of the most common infectious attacks in children, Pediatrics significant problem for many reasons: its incidence, the polymorphism of clinical manifestations, its potential severity (renal scarring), the possibility of revealing a uropathy.

Objective Evaluate the incidence, morbidity and long-term acute (hypertension, renal failure), the proportion of bacterial strains involved and how they supported.

Materials and Methods Retrospective study done on the records of patients hospitalized in pediatric ward from 01-01-2009 until 31-12-2009.

130 patients were the subject of this study.

Results Incidence: 4.64\%.

Frequently females (sex ratio 0.68 ). The age group most affected is from 30 days to 05 years (range $30 \mathrm{~d}$ and 15).
Fever was noted in 110 patients, 44 patients complained of urinary symptoms. The gross hematuria was observed in 07 patients.

leukocytosis was present in $84.62 \%$ of cases; an ESR above 30 in the first hour in $34.61 \%$ cases. CRP was positive in $65.38 \%$ of patients.

E coli in $22.38 \%$ cases, followed in descending order of pneumoniedans klebsiella, pseudomonas aeroginosa, Proteus, enterococcus.

Ultrasound renal disease $17.16 \%$ (7.58\% urétérohydronephrose).

The UCR pathological in $9.70 \%$ (6\% RVU).

Pathological IVU 5.22\% (3\% urétérohydronéphrose).

Conclusion This study confirmed the frequency of UTI in a pediatric setting. However, great efforts are still needed to better support her.

Better knowledge of bacteriology Local: prevalence of germs, sero-typing, with ATB resistance;

The long-term prophylactic treatment of UI also remains to be defined.

Supprimer RépondreRépondre Faire suivreDéplacerImprimer Actions Suivant Précédent.

\section{SEVOFLURANE ANESTHESIA SIDE EFFECTS IN PEDIATRIC PATIENTS UNDERGOING RADIOTHERAPY}

doi:10.1136/archdischild-2012-302724.1534

${ }^{1} \mathrm{M}$ Feltrin, ${ }^{2} \mathrm{AFY}$ Centroni, ${ }^{3} \mathrm{MA}$ Santos, ${ }^{1} \mathrm{CM}$ Vaz, ${ }^{1} \mathrm{MC}$ Nascimento, ${ }^{4} \mathrm{~J}$ Ropero, ${ }^{1} \mathrm{PG}$ Aires, 'S Taniguchi. 'Albert Einstein Hospital; ${ }^{2}$ Oncology; ${ }^{3}$ AMA Paraisópolis, Albert Einstein Hospital; ${ }^{4}$ UFABC, São Paulo, Brazil

Background and Aims Sevoflurane anesthesia is related to high incidence of emergence agitation in pediatric patients.

Methods Our retrospective study included 38 pediatric patients with mean age $29 \pm 3.94$ months, weight mean $14.64 \pm 0.55 \mathrm{~kg}$ undergoing radiotherapy.

Results Patients with retinoblastoma 55.26\% (21), meduloblastoma $23.68 \%$ (9) and malignant neoplasm of cerebellum $21.10 \%$ (8) which received radiotherapy $27.79 \pm 2.16$ sessions were studied.

Sevoflurane $8 \%$ were administered to $100 \%$ of these patients for anesthesia induction and maintenance.

The anesthesia duration was $32.62 \pm 2.41$ minutes.

Emergence agitation, nausea and allergic reaction were observed.

The incidence of emergence agitation during the anesthesia recovery was observed in $84.21 \%$ (32) compared to $15.79 \%$ (6) no agitation side effect patients.

Nausea was observed in $10.53 \%$ and allergic reaction recorded in $5.26 \%$ of patients.

Either propofol $0.5-4.4 \mathrm{mg} / \mathrm{kg}$ administered to $34.38 \%$ (11) patients or nalbuphine $0.1-0.15 \mathrm{mg} / \mathrm{kg}$ given to $6.25 \%$ (2) patients or fentanyl $2-3.6 \mathrm{mg} / \mathrm{kg}$ given to $3.12 \%$ (1), controlled the emergence agitation induced by sevoflurane anesthesia.

No treatment was applied to $56.25 \%$ (18).

Conclusions The association of propofol or nalbuphine to sevoflurane was effective controlling emergence agitation induced by sevoflurane anesthesia in children undergoing radiotherapy.

Stable vital signs were registered previously and after sevoflurane.

One case of anaphylactic reaction was observed in patients undergoing anesthesia with sevoflurane.

\section{5 \\ NATIONAL TASK FORCE ON SAFE PEDIATRIC MEDICATIONS: IMPROVE THE ACESS TO LIQUID FORMULATIONS}

doi:10.1136/archdischild-2012-302724.1535

${ }^{1} \mathrm{O}$ Carvalho, ${ }^{1} \mathrm{D}$ Duarte, ${ }^{2} \mathrm{C}$ Teixeira de Barros, ${ }^{3} \mathrm{D}$ Palma, ${ }^{4} \mathrm{H}$ Jardim, ${ }^{5} \mathrm{M}$ Almeida, ${ }^{6} \mathrm{~T}$ Tomé ${ }^{1}$ INFARMED, IP; ${ }^{2}$ Faculdade de Farmácia, Universidade de Lisboa, Lisbon; ${ }^{3}$ Hospital Dr. José Almeida, Cascais; ${ }^{4}$ Centro Hospitalar do Porto, EPE, Porto; ${ }^{5}$ Dep. Pediatria CHL Norte, Lisboa; ${ }^{6} \mathrm{CHL}$ Central, MAC, Lisbon, Portugal 
Background and Aims The availability of appropriate medicines for pediatric patients remains a challenge in any Health System. To evaluate the extent of this limitation in Portugal, the INFARMED, I.P., conducted the present study aiming at 1) knowing which extemporaneous formulations were prepared/used in hospital settings and 2) identifying which of these have a liquid formulation medicine available in Portugal, EU or USA.

Methods A cross sectional study was performed in nine Hospitals in Portugal regarding the collection of 2010 data on the use and production of extemporaneous formulations. The information was gathered trough a questionnaire. Data analysis was restricted to medicines with more than 1000 formulations prepared or prescribed to more than 100 patients.

Results Thirty three medicines met the defined criteria. They were included in groups A and C of the ATC classification (Alimentary Tract and Metabolism and Cardiovascular System) with 8/33 (24.24\%) each, followed by Anti-infectives for Systemic Use and Nervous System with $5 / 33(15.15 \%)$ each. It was realized that $20(75.76 \%)$ have a licensed oral liquid formulation either in Portugal, EU or USA. In Portugal 7 (21.21\%) have or had a market authorization no longer available due to industrial ending. In addition, different hospitals prepare the same medicine in distinct formulations.

Conclusions The results confirmed the needs of Portugal in this area, identified potential lack of interest of the industry and recommend that strong action should be taken by the Regulatory Authority in the implementation of industrial manufacture authorization of small GMP batches of these medicines.

\section{PHARMACOEPIDEMIOLOGY OF OCULAR PRESCRIPTIONS IN PAEDIATRIC OUTPATIENTS IN PORDENONE PROVINCE}

doi:10.1136/archdischild-2012-302724.1536

G Montanari, P Schiaulini. Clinical Research Department, FIMP Friuli Venezia Giulia, Sacile, Italy

Background and Aims The use of ocular drugs in paediatrics is often "off-label", concerning both safety in relation to the age and efficacy. For this reason we have deemed it necessary to examine prescribing habits of family paediatricians (pdf).

Methods Each pdf of Pordenone province (315.323 inhabitans) was sent a questionnaire where it was requested to list the ocular drugs usually prescribed, why they were prescribed and any side effect observed. They were also requested to confirm any use of dietary supplements or other medical devices.

Results All 35 pdf (34.440 chidren, aged 0-14 years) filled in the questionnaire. The most commonly prescribed drugs were antibiotics, anti-histamine agents and mast cell stabilizers for bacterial and allergic conjunctivitis. Only topical drugs were used. Children affected by serious ocular diseases were referred to ophtalmologists and of these only four assumed drugs for vernal keratoconjunctivitis and glaucoma (cyclosporine, timolol, dorzolamide and bimatoprost). Only minor adverse reactions (conjunctival hyperaemia, lid swelling) were found, even if potentially dangerous drug associations are still used (i.e. associations with steroids and/or sympathomimetic decongestants). No dietary supplements or medical devices were prescribed.

Conclusions Many ocular drugs lack reliable proof of efficacy and safety in paediatrics but fortunately their use outside the hospital seems limited. Nevertheless their use can probably be improved. Our research confirms the need to widen clinical studies of ocular drugs in paediatrics, not only concerning limited controlled trials but also their rational use.

1537 EFFECTIVENESS OF MELATONIN IN TREATING SLEEP
PROBLEMS IN CHILDREN - PARENT SATISFACTION SURVEY

'A Gupta, ${ }^{2} \mathrm{C}$ Varthamanan. ${ }^{\top}$ Addenbrookes Hospital, Cambridge; ${ }^{2}$ Bedford Community Paediatrics, Bedford, UK

Background and Aim Melatonin is not licensed for children in UK. Limited evidence is available about its efficacy and safety. We assessed parents' satisfaction with melatonin for treatment of sleep problems in children.

Methods 27 children who were prescribed melatonin by community paediatricians at Bedford, UK were randomly selected. Structured questionnaire was given to their parents.

\section{Results}

1. Parents' overall assessment of response to melatonin treatment - Good (63\%), Average (33\%), Poor (4\%).

2. Analysis of age group of children with good response. $1-5$ years ( 3 out of 3 children i.e. 100\%), 6-10 years (7/12 i.e. $58 \%$ ), $11-16$ years $(7 / 10$ i.e. $70 \%)$, Over 16 years $(0 / 2$ i.e. $0 \%)$.

3. Effect on sleep when melatonin was stopped (in 18 children) - worsening (72\%), same (28\%), improvement (0\%).

4. All the children had associated problems $-81 \%$ behavioural (autism, ADHD), 19\% structural/chromosomal. 41\% were in mainstream school, 55\% special need school and $4 \%$ left school.

5. Improvement in behaviour secondary to improvement in sleep - yes $(26 \%)$, No $(74 \%)$.

6. Improvement in quality of life of parents secondary to fewer interruptions to their sleep - Yes (77\%), No (23\%).

7. Only 1 child had side effects including headache, confusion and tiredness while taking melatonin. He was on high dose of $10 \mathrm{mg} /$ day.

Conclusion Most parents reported improvement in sleep of their children after being started on melatonin. Also majority reported better quality of life due to less interruption to their sleep.

\section{USE OF PROPRANOLOL FOR TREATING EPISTAXIS - FIRST EXPERIENCES}

doi:10.1136/archdischild-2012-302724.1538

'B Bjelakovic, ${ }^{2 M}$ Bojanovic, ${ }^{3} \mathrm{~S}$ Lukic, ${ }^{1} \mathrm{G}$ Kostic, ${ }^{4} \mathrm{~N}$ Zivkovic, ${ }^{5} \mathrm{~V}$ Vukomanovic, ${ }^{5} \mathrm{~S}$ Prijic, ${ }^{6} B$ Marinkovic. 'Clinic of Pediatrics, Clinical Center, Medical Faculty, University of Nis; ${ }^{2}$ Clinic of Othorinolaringology, Clinical Center, Medical Faculty, University of Nis; ${ }^{3} \mathrm{Clinic}$ of Neurology, Clinical Center, Medical Faculty, University of Nis; ${ }^{4}$ nstitute of Pathology, Medical Faculty, University of Nis, Nis; ${ }^{5}$ Mother and Child Health Institute, 'Dr Vukan Cupic', Belgrade; ${ }^{6}$ Clinic of Othorinolaringology, Clinical Center, Nis, Serbia

Beta blockers are considered to be the most common prescribed class of drugs in treating cardiovascular diseases. However they are very useful in treating other conditions, such as migraine, glaucoma, hemangiomas, cirrhosis, etc.

We hypothesized that some beta blockers characteristics including their negative inotropic, peripheral vasoconstrictor and antiangiogenic effects might be potentially useful in the management of children with epistaxis.

To test this we sought to determine the efficiacy of propranolol as a second line therapy in children with reccurent primary epistaxis, resistant to conventional management. From June 2010 to October 2011, a total of six children with this features were seen a our institution.

The overall effectiveness of propranolol for terminating epistaxis, given in dosage of $1.5-2 \mathrm{mg} / \mathrm{kg} /$ day, three times a day, was successful in all six treated children (100\% efficacy) becoming evident within 24 hours after the after the initiation of treatment. The epistaxis free interval period lasted at least one year, in five children and 43 days in one children.

Based on our first experiences with propranol, we believe this drug could be promising treatment option for children with primary epistaxis.

\section{LENGTH OF HOSPITAL STAY IN CHILDREN WITH ACUTE VIRAL PNEUMONIA TREATED WITH CORTICOSTEROIDS, A RETROSPECTIVE STUDY}

